\title{
INSERÇÃO SÓCIOCOMUNITÁRIA COMO ALICERCE DOS PROCESSOS FORMATIVOS DAS ESCOLAS PROFISSIONAIS DE MOÇAMBIQUE1
}

\author{
Lucília Regina de Souza Machado²
}

\begin{abstract}
Resumo
Com este artigo, buscou-se resgatar a discussão sobre diretrizes, alcances e limitações referentes à efetivação de bases sociocomunitárias de escolas profissionais. Para tanto, recuperou resultados de uma pesquisa realizada em 2011 em quatorze instituições moçambicanas criadas para serem uma referência inovadora em matéria de educação profissional destinada a comunidades com predomínio de culturas tradicionais. $\mathrm{O}$ texto traz elementos teóricos sobre saberes comunitários tradicionais, conhecimentos escolares e desenvolvimento local à luz de algumas reflexões sobre a realidade social e cultural moçambicanas. Aborda aspectos do percurso metodológico realizado para a coleta de dados e os principais achados sobre um dos pontos focalizados por essa pesquisa, notadamente a problemática representada pelo desafio da efetivação da inserção sociocomunitária das escolas profissionais de Moçambique.
\end{abstract}

Palavras-chave: escolas profissionais; experiências educativas; comunidades tradicionais.

\section{INSERCIÓN SÓCIOCOMUNITARIA COMO ALICERCE DE LOS PROCESOS FORMATIVOS DE LAS ESCUELAS PROFESIONALES DE MOZAMBIQUE}

\section{Resumen}

Con este artículo, se buscó rescatar la discusión sobre directrices, alcances y limitaciones referentes a la efectividad de bases sociocomunitarias de escuelas profesionales. Para ello, recuperó resultados de una encuesta realizada en 2011 en catorce instituciones mozambiqueñas creadas para ser una referencia innovadora en materia de educación profesional destinada a comunidades con predominio de culturas tradicionales. El texto trae elementos teóricos sobre saberes comunitarios tradicionales, conocimientos escolares y desarrollo local a la luz de algunas reflexiones sobre la realidad social y cultural mozambiqueña. Aborda aspectos del recorrido metodológico realizado para la recolección de datos y los principales hallazgos sobre uno de los puntos focalizados por esa investigación, notadamente la problemática representada por el desafío de la efectividad de la inserción sociocomunitaria de las escuelas profesionales de Mozambique.

Palabras clave: escuelas profesionales; experiencias educativas; comunidades tradicionales.

\footnotetext{
${ }^{1}$ DOI: https://doi.org/10.22409/tn.16i31.p27371

2 Doutora em Educação, vinculada ao Programa de Pós-Graduação em Gestão Social, Educação e Desenvolvimento Local do Centro Universitário Una. E-mail: Ismachado@uai.com.br
} 


\section{Introdução}

O modelo curricular e pedagógico das Escolas Profissionais de Moçambique, que veio à luz em 1999, foi concebido, conforme Azevedo \& Abreu (2007), para ser um avanço em relação à educação profissional tradicional moçambicana baseada nos princípios do aprender fazendo e na aprendizagem com grupo de pares.

Dentre outros princípios, trazia a proposta de que os cursos oferecidos se pautassem pela relevância com respeito às necessidades locais e regionais e que tivessem como suporte uma rede de apoio de base comunitária. Eles deveriam ser acessíveis e conduzir a qualificações conhecidas, de imediata e clara compreensão por todos, sem deixar de lado a produção e incorporação de inovações.

$O$ argumento era de que as Escolas Profissionais (EP) deveriam se firmar sobre uma base de liderança institucional e pedagógica bastante vigorosa e que isso só poderia ser construído com ampla participação de todos, especialmente a comunitária. Ou seja, deveriam desenvolver a capacidade de tomar em consideração as dinâmicas culturais locais de desenvolvimento social e cultural. Azevedo, coordenador do projeto dessas escolas, e Abreu, seu consultor permanente, assim justificam essa aspiração:

A desenvolvimento associamos também uma vontade de participação, de autonomia e de mobilização das potencialidades endógenas de um território concreto. Aí a valorização matricial vai para todas as perspectivas e para todas as acções concretas, que incorporem o papel preponderante e crucial do homem, de cada pessoa e das comunidades locais, inscritas na sua matriz histórica específica. Por isso, o desenvolvimento deve aliar, por um lado, os esforços voluntaristas das administrações e dos governos e, por outro lado, a intervenção concreta dos actores e das comunidades. São estes que podem construir os processos do seu desenvolvimento, por mais pobres, mais iletrados, mais desorganizados que sejam e estejam, eles são os protagonistas principais, ninguém os substitui nos seus próprios espaços e nos seus próprios passos, a sua cultura é o ponto de partida, o fio estruturante da sua viagem. (AZEVEDO; ABREU, 2007, p.16).

Entendem os autores que é dessa forma, a do "[...] envolvimento nos contextos sociais locais, combinando aí o local e o global, a tradição e a ciência, o prescrito e o aberto, a norma e a página em branco" (AZEVEDO; ABREU, 2007, p.19) que a educação pode melhor contribuir com a luta em prol do desenvolvimento moçambicano. 
Deixam claro que essa participação social na construção dessas escolas deve ser alargada para que, de fato, elas sejam das comunidades locais. Isso implicaria, por um lado, aberturas recíprocas para o estabelecimento de acordos com respeito ao delineamento e desenvolvimento de atividades educativas. Por outro, a sabedoria para reconhecer as dificuldades, mas também as potencialidades a respeito dos recursos existentes no meio social tendo em vista mobilizá-los como mediação dos processos de ensino-aprendizagem.

Destacam a importância da "[...] valorização constante da ligação da escola e de cada área de estudos ao meio envolvente e às suas dinâmicas sociais mais significativas (que variam de local para local)". (AZEVEDO; ABREU, 2007, p.23). Da parte das empresas, fornecimento de apoio material, conhecimento técnico, estágios e de possibilidades de inserção profissional aos estudantes formados. Da parte das escolas (algumas com práticas de formação em alternância) e de seus alunos e professores, o estudo das necessidades da população local, a produção de bens e serviços comunitários, a recuperação do saber-fazer tradicional e 0 compartilhamento de conhecimentos com as comunidades.

Braga (2018, p.60) informa que:

Cada escola tem um Projecto Educativo territorializado, que Ihe confere uma identidade própria e a distingue pela especificidade da sua proposta educativa, de tal modo que as EP desempenham, para as regiões onde estão inseridas, um papel de facilitador do desenvolvimento local e regional. As EP, eminentemente rurais, podem ser de natureza pública, privada e comunitária e gozam de autonomia administrativa, financeira, pedagógica e cultural. Existem 44 escolas em funcionamento (ano de 2014), sendo seus promotores diversas entidades. As escolas profissionais já realizaram 12 ciclos de formação, tendo qualificado até hoje cerca de 32 mil jovens em termos técnico-profissionais. Actualmente frequentam estas escolas 11 mil alunos, que têm à sua disposição vários cursos. Têm acesso à frequência das EP os alunos saídos da Escola Primária Completa, com a sétima classe concluída (escolaridade mínima obrigatória em Moçambique).

Azevedo (2017), porém, alerta para mudanças societárias e seus reflexos em contraposição a projetos como esses das EP: a aceleração do tempo, a rarefação dos espaços tradicionais, a hiper-experimentação e a hiper-estimulação contínua inibidoras do encontro de cada um consigo mesmo e do distanciamento crítico face ao quotidiano, as frivolidades nas relações, o desprezo pelo cuidado interpessoal, a 
falta de profundidade, o apelo ao consumismo, a apatia e a passividade, dentre outros. Segundo ele, '[...] há mais fechamento dos pequenos grupos de 'amigos' sobre si mesmos, em pequenas ilhas e 'comunidades de mesmidade', como dizia Bauman, em que o longe está cada vez mais perto, mas o mais perto e os seus problemas estão também mais longe [...]". (AZEVEDO, 2017, p.8).

Portanto, faz sentido resgatar contribuições para essa reflexão vindas de uma pesquisa realizada ainda em 2011 sobre as Escolas Profissionais de Moçambique, em atendimento à demanda da Fundação Portugal África, do Ministério da Educação de Moçambique e do Instituto Português de Apoio ao Desenvolvimento - Ipad.

Essas escolas estavam, à época, completando dez anos de idade e seu Regulamento estabelecia a necessidade de uma avaliação externa do modelo curricular e pedagógico adotado.

A pesquisa de campo foi realizada por dois consultores externos, do Brasil e de Portugal, com a colaboração de membros da Unidade Técnica de Apoio ao Programa das Escolas Profissionais de Moçambique (UTA/PEP) do Ministério da Educação de Moçambique e apoios das direções provinciais e das escolas, dos professores, alunos e comunidades. O consultor português realizou a pesquisa em EPs no norte do país e a consultora brasileira em EPs do centro e do sul.

A pesquisa foi realizada em 14 escolas de oito províncias de Moçambique: EP de Moamba e EP S. Francisco (Província de Maputo); EP de Inhamissa (Província de Gaza); EP de Inharrime e EP de Massinga (Província de Inhambane); EP de Mangunde e EP de Caia (Província de Sofala); EP de Chimoio (Província de Manica); EP D. Bosco e EP Songo (Província de Tete); EP llha de Moçambique (Província de Nampula); EP de Montepuez, EP de Mariri e EP de Ocua (Província de Cabo Delgado).

No conjunto, essas EPs ofereciam 45 cursos: dez em Carpintaria / Marcenaria; seis em Serralheria Civil / Soldagem; cinco em Serralheria de Manutenção Mecânica; cinco em Formação de Pedreiro; cinco em Agropecuária; três em Eletricidade para Edificações; dois em Mecânica de Automóvel; dois em Serviços de Mesa e Bar; um em Serviço Administrativo, um em Eletricidade para Bobinagem; um em Lanternagem; um em Jardinagem / Floricultura e um em Horticultura / Fruticultura. 
Foram ouvidos representantes de direções provinciais, diretores de EPs, diretores adjuntos pedagógicos, professores, alunos, pais ou encarregados da educação dos alunos, autoridades e líderes locais, empregadores e representantes de organizações não governamentais.

Com este artigo, tem-se o propósito de resgatar especificamente as contribuições dessa pesquisa para a discussão sobre as bases sociocomunitárias das Escolas Profissionais de Moçambique tanto no que diz respeito às suas diretrizes quanto ao alcance e limitações para a efetivação desse pressuposto.

\section{Comunidade, comunidade tradicional, inserção sociocomunitária e educação}

Para abordar a categoria inserção sociocomunitária sobre a qual trata este artigo, faz-se necessário tecer algumas considerações específicas com respeito ao termo comunidade. Usado de diferentes formas e em referência a muitos contextos, assume diversos significados.

Trata-se sempre de uma entidade social e/ou espacial referida ou a um grupo ou a uma agremiação, associação, corporação, empresa, organização, instituição. Necessariamente, as pessoas envolvidas podem não compartilhar a existência em um mesmo lugar físico. Basta que estejam em comunhão e reciprocidade, ter algo material ou imaterial partilhado, o que as leva a tecer laços e identificações. $O$ arranjo pode estar estruturado por disposições, interesses e códigos culturais e funcionais específicos (religiosos, econômicos, científicos, profissionais etc) ou por ambientes e contextos onde se dão as relações sociais (rural, urbano, virtual etc). Uma comunidade é, assim, descrita por Ander-Egg:

[...] um agrupamento organizado de pessoas que se entendem como unidade social, cujos membros participam de alguma característica, interesse, elemento ou função comum, com consciência de pertença, situadas numa determinada área geográfica na qual a pluralidade das pessoas inter-aciona mais intensamente entre si que noutro contexto. (1982, p.25).

O imaginário da integração social está, em geral, presente, mesmo quando a complexidade das relações sociais tecidas aponta para a existência de diversidades, contradições e conflitos internos. Apesar disso, trata-se sempre de um lugar histórico, cultural e relacional a partir do qual se estruturam, pelo entrecruzamento, elementos 
formais e informais e se definem identidades individuais e coletivas. De sorte que identificar, descrever e explicar os modos de funcionamento, de organização e de participação de comunidades é sempre um desafio para quem deseja conhecê-las, estudá-las ou interpretá-las.

As chamadas comunidades primitivas ou gentílicas têm como características a propriedade comum sobre os meios de produção e a distribuição equitativa dos resultados da produção social. Muitas comunidades ancestrais ou tradicionais assim se identificam mesmo que já atravessadas de algum modo pelo desenvolvimento da divisão social de trabalho e da propriedade privada dos meios de produção.

Foi a partir do Romantismo, movimento artístico, intelectual e filosófico que surgiu na Europa no final do século XVIII, que o termo comunidade passou a ser utilizado para indicar a forma da vida social caracterizada por um vínculo orgânico, intrínseco e apurado entre os seus membros. Como resistência ao racionalismo e iluminismo, essa corrente apelava às emoções para celebrar a natureza e os valores do conservadorismo. A clássica contraposição estabelecida por Ferdinand Tönnies entre dois tipos de organização social, sociedade versus comunidade, em obra publicada em 1887 (Comunidade e Sociedade), recebeu influências desse movimento.

Sawaia (1996, p.42) explica que:

Marx difere de forma significativa das implicações valorativas tradicionais que sustentam o contraste entre comunidade $e$ sociedade. Sua concepção dialética materialista da sociedade situa historicamente o debate comunidade e sociedade no capitalismo, isto é, no centro da luta de classes. A sociedade, na teoria marxista, não é harmoniosa, mas conflitiva, sendo que o harmonioso e o conflito não são determinados pela presença ou ausência de valores comunitários, mas por problemas nas relações de produção. $O$ individualismo, inimigo das relações comunitárias, e fruto do "fetiche" da mercadoria, do trabalho alienado e produtor de mais valia. (aspas no original).

Porém, segundo Sawaia (1996, p.42):

Marx também se rendeu ao comunitarismo, enquanto ética da vida social digna e justa. Mas sua ideia de comunidade não se refere à volta ao passado perdido, ou à recuperação dos valores comunitários em nível local ou nacional para superar as agruras do individualismo. Ele se afasta de modelos baseados no tradicionalismo e no localismo, pois acredita na vasta associação de nações na comunidade transnacional e encontra na classe trabalhadora a estrutura para a redenção ética da humanidade, como demonstra o apelo que fez no 
Manifesto do partido comunista (1983:45): "Proletariado de todos os países, uni-vos". (aspas no original).

A autora estende essa análise de Marx para os dias atuais para reafirmar o que nesse Manifesto foi anunciado: o desmoronamento pelo processo de mundialização do capital de todas as fronteiras tradicionais de apartação das nações e das pessoas, para o qual concorrem favoravelmente as tecnologias de informação e comunicação. Isso, contudo, não implicou em desconsiderar a importância dos estudos sobre a gênese e funcionamento das comunidades, pois o mesmo movimento da derrubada das antigas fronteiras tem feito despontar formas de diferenciação e de discriminação, algumas já existentes e outras emergentes. Com isso, as questões da relação com o outro e das identidades reaparecem com força como reação em busca de soluções de integração.

O significado de comunidade vem passando, assim, por transformações de relevo, dentre as quais as que põem ênfase nas referências ao caráter local das relações sociais estabelecidas, a despeito do quanto no local se reproduz o global e vice-versa, os sentimentos e atitudes heterogêneos, a complexidade na sua forma mais simples.

São movimentos dialéticos que precisam ser considerados nos estudos sobre as chamadas comunidades tradicionais e os processos educacionais que nelas se desenvolvem. Por exemplo, as articulações e contradições entre a educação escolar regular e a educação tradicional com características comunitárias.

Tal coexistência se faz de maneira informal, ampla, nem sempre aberta e pacífica, mas sempre contextualizada em situações vivenciais, em rituais de reprodução de valores culturais e ancestrais. Por vezes, é a educação tradicional que impõe sua influência à educação escolar. Em outras, é a escola que recorre a mediações sociais, instrumentais e simbólicas para fazer sua inserção sociocomunitária.

Essa intercalação de uma educação em outra resulta em processos sempre abertos à indeterminação. Às vezes, é a comunidade que faz valer seus princípios e regras utilizando-os para empapar a educação escolar, seja ela de caráter geral ou profissional. São referências difusas e presentes em todos os lugares e momentos, na convivência no seio das famílias e nos espaços públicos, realizando-se pela experiência. 
A inserção sociocomunitária se apresenta para as escolas, portanto, como uma disputa com as influências exercidas pelos adultos das comunidades tradicionais, com a linguagem da qual essas se servem para se comunicar, com os instrumentos mediadores que promovem a impregnação de determinados modos de pensar e viver.

Resta a dúvida sobre os limites e possibilidades dessa trama para a efetivação do comunitarismo movido pela ética da vida social digna e justa.

\title{
3. Saberes comunitários tradicionais, conhecimentos escolares e desenvolvimento local
}

Libombo et al. (2017) lembram que o tema do desenvolvimento local tem ocupado lugar de destaque nos debates e agendas políticas, sociais e econômicas de organismos internacionais e de países como Moçambique, que ainda enfrentam contradições e entraves à (re)construção nacional, alguns decorrentes da herança e resquícios colonialistas, mas outros inerentes às limitações que vieram a seguir, tais como: economia vulnerável, dependência de recursos externos, falta de investimentos, práticas centralizadoras, insensibilidade às particularidades e às especificidades locais, a não qualificação técnica e a baixa escolaridade da força de trabalho, a evasão de profissionais para o exterior, sem contar as sabotagens. Os autores informam que:

\begin{abstract}
A redução da pobreza absoluta em Moçambique, assim como o crescimento econômico, tem entraves sérios, sem um desenvolvimento sustentável efetivo da agricultura. De acordo com o programa quinquenal do governo (2015-2019), continua definido como objetivo central o "combate" à pobreza como forma de melhorar as condições de vida da população e coloca-se a agricultura como a base do desenvolvimento econômico e social do país, por esta ter um papel determinante na redução da pobreza. (LIBOMBO et al., 2017, p. 136). (aspas no original).
\end{abstract}

A esse respeito, dados informados por esses autores são importantes. Primeiro, que $70 \%$ da população moçambicana vivem na zona rural sendo que grande parte desse contingente encontra-se abaixo da linha de pobreza absoluta. Segundo, que a agricultura contribui com cerca de $50 \%$ do PIB e $75 \%$ das exportações do país. 
Para eles, o conceito de desenvolvimento local é importante por dar visibilidade e destacar a necessidade de se considerar as diversidades e as particularidades de contextos locais, dos territórios, cada qual com suas necessidades e demandas. Entendem ser fundamental, como concepção de desenvolvimento, reconhecer a importância dos processos endógenos, dos espaços, ações e manifestações das comunidades locais.

A reflexão de Nguiraze e Aires (2011), ao comentar o que seria a participação cidadã no sentido ético dos agentes do poder estatal moçambicano, conduz, contudo, à problematização do que seria a ação comunitária, pois reificada pode se transformar em mero objeto ou

[...] um encontro das ações na direção daquele que demanda ou é estimulado a demandar. Criam-se, inclusive, os canais para receber as demandas. Sob diferentes concepções, a reificada comunidade ora surge como o demandante, ora é evocada como uma alternativa para coletivizar os pedidos ou, ainda, é empregada como um termo substituto para referir-se à população carente. (NGUIRAZE; AIRES, 2011, p.42).

Previnem esses autores com respeito a esse processo de reificação, pois, segundo eles:

Comunidade - e suas derivações - é um termo substantivo para outras denominações que tanto pode dizer respeito aos limites físicos ou territoriais, como também à adesão de pessoas a determinadas ideias, enfeixando-as em um senso comum legítimo. E ainda o termo comunidade é frequentemente substantivado. Passado, desta forma, a substituir o sujeito da ação. (NGUIRAZE; AIRES, 2011, p.43).

Nguiraze e Aires (2011) preferem falar em inserção social, um processo que implicaria em participação efetiva e intervenção ativa da população rural pobre moçambicana na superação dos fatores estruturais, que a levam à falta de acesso à renda, educação, oportunidade de trabalho, dentre outros direitos. Eles enfatizam o caráter político dessa inserção referindo-se à intromissão dessa população na promoção da mudança das suas condições de vida, o que implicaria instituir ou por em vigor novas relações sociais, que propiciem a construção da cidadania.

Martins e Azevedo (2015) adotam o termo sóciocomunitária para se referirem à educação inserida no processo de desenvolvimento local. Esse também é o termo 
utilizado nos documentos do Programa das Escolas Profissionais de Moçambique. Lembram que há bastante consenso com respeito à ideia de círculo virtuoso entre desenvolvimento e educação, mas que se essa última, tal como assinalou Cardoso (2011), "[...] não tiver como premissas determinados aspetos, como uma lógica participativa, flexível, local, prática e equitativa, pode mesmo ser contraproducente no que respeita ao desenvolvimento das comunidades" (MARTINS; AZEVEDO, 2015, p.170).

Mas como assegurar essa lógica informada por tais critérios e requisitos se a falta de princípios de unidade territorial, política e cultural caracteriza as vinte etnias ou quantidade semelhante de grupos linguísticos que vivem em Moçambique? Segundo Namuholopa e Vettorassi (2017, p.127), ao definir as fronteiras desses grupos ou etnias, o colonizador baseou-se em "[...] acidentes naturais (rios e montanhas) e, noutros casos, em linhas imaginárias contorcidas arbitrariamente. Assim, é frequente encontrar o mesmo povo dividido, um de um lado e outro de outro lado da fronteira." Essa realidade multiétnica e multilinguística, fragmentada artificialmente, é também coabitada, no atual Moçambique, por povos de origem chinesa, árabe e indiana.

Partes consideráveis dessas etnias formam culturas orais, que trazem conhecimentos e saberes de longa data, acumulados e atualizados ao serem repassados na sucessão de cada geração. Segundo Castiano (2005, s/p),

\begin{abstract}
Há saberes ancestrais sobre plantas e animais, sobre as causas de certas doenças e procedimentos para o seu tratamento, sobre técnicas de construção e de cultivo, saberes estes que são usados para resolver problemas concretos locais. Estes saberes subsistem, na maioria dos casos, lado a lado com os saberes modernos, não necessariamente numa relação de exclusão mútua. Alguns deles (por exemplo, relacionados com o uso de ervas e insectos para o tratamento de determinadas doenças) estão em perigo de desaparecer da memória colectiva das pessoas das aldeias.
\end{abstract}

O reconhecimento da importância de tais saberes ancestrais motivou a homologação, no Brasil, da Lei 9.394/1996, modificada pelas leis 10.639/2003 e 11.645/2008, e suas diretrizes referentes à inclusão, nos currículos da educação básica, de conteúdos culturais africanos, contemplando também os de povos originários indígenas. Contudo, os diálogos entre o conhecimento tradicional e o científico e as intervenções pedagógicas neles referenciadas, tal como propõem as 
etnociências, são complexos, tanto que Verrangia toma emprestada a expressão de uma rezadeira para dizer que "é preciso muita ciência para esse desafio" (2010, s/p). Por conta disso, mas não somente disso, Castiano (2005, s/p) lamenta:

Infelizmente, em vez de estes saberes terem sido integrados num debate argumentativo e terem sido submetidos à rigidez e exactidão da tradição científica, eles continuam cobertos por um véu de certo misticismo. $O$ véu do misticismo com que se cobrem certos saberes tradicionais afecta profundamente 0 processo de integração, disseminação e validação dos saberes locais para a sua projecção num contexto mais universal da produção e circulação do conhecimento científico.

Apesar disso, o autor reconhece que, na educação moçambicana, iniciativas voltadas para essa integração têm sido feitas, tais como e dentre outras: a participação de comunidades na formatação de currículos, o emprego de idiomas maternos em certas disciplinas, o convite a artesãos locais para ensinar conteúdos de seu domínio, a utilização de oficinas situadas no território como espaço de visita de alunos, o ensino por pessoas mais velhas da história local e dos usos e costumes comunitários. (CASTIANO, 2005, s/p).

Para o autor, o ensino de saberes locais apresenta diversas vantagens. Dentre elas, a abertura de possibilidades para a inserção dos alunos no sistema ocupacional local e o aprendizado, por eles, de normas e valores semelhantes aos de sua socialização familiar. Além disso, a finalidade de fazer o resgate do que foi negado pelo colonizador. Segundo ele,

[...] no tempo colonial, as diversas versões do currículo para as crianças negras ou indígenas eram desenhadas consciente e sistematicamente para responder ao projecto do "imperialismo cultural", quer dizer, com a intenção declarada de dominar e inferiorizar saberes, valores e práticas de povos autóctones.

Assim, embora aqueles programas estivessem voltados, por exemplo, para a prática da agricultura ou ainda para o domínio de alguns ofícios geralmente aplicáveis nas localidades, o sistema nunca valorizou as cosmovisões e tradições culturais locais. Não havia espaço para uma relação argumentativa entre os saberes. (CASTIANO, 2005, s/p). (aspas no original).

O autor admite avanços na educação moçambicana com respeito à legitimação desses saberes traduzidos por formas de institucionalização da 
participação comunitária na definição de conteúdos de ensino-aprendizagem, pelo estímulo à interação entre os saberes, práticas e valores locais e os universais e pelo reconhecimento da importância do professor na realização dessas mediações e na promoção da inserção comunitária nos projetos e espaços escolares. Porém, se acautela e observa que:

[...] não podemos de forma nenhuma nem romantizar o tradicionalismo da comunidade e nem ser muito optimistas no sentido de que o currículo local é recebido de mãos abertas por professores e pelas comunidades.

De facto, acho que seria um engano deduzir que a comunidade pode participar curricularmente só em assuntos que dizem respeito às tradições locais. Uma atitude romântica, tradicionalista e reduccionista deste género seria simplista em relação às potencialidades de desenvolvimento existentes nas comunidades. (CASTIANO, 2005, s/p).

São tensões e possibilidades, que vêm sendo densamente argumentadas por Boaventura de Sousa Santos, quando critica e propõe a ultrapassagem do que chama de pensamento abissal por meio do resgate do que também entende como epistemologias do Sul e ecologia de saberes.

A esse respeito, Santos (2007, p.73) se refere "[...] aos conhecimentos populares, leigos, plebeus, camponeses ou indígenas do outro lado da linha, que desaparecem como conhecimentos relevantes ou comensuráveis por se encontrarem para além do universo do verdadeiro e do falso". Ele advoga "[...] um aprender com o Sul usando uma epistemologia do Sul" [...] (SANTOS, 2007, p.85), uma ecologia de saberes baseada na idéia de que o conhecimento é interconhecimento.

\section{Percurso metodológico}

Este artigo resgata parte de uma investigação, que foi realizada com a finalidade de analisar aspectos valorativos, normativos e motivacionais que servem de referência a avaliações subjetivas do modelo de referência do Programa das Escolas Profissionais de Moçambique.

Por se referir a pontos de vista, entendimentos, compreensões, concepções, perspectivas, visões, ângulos, olhares, significados sociais e sentidos pessoais, esse 
tipo de investigação recebe usualmente, a designação de pesquisa qualitativa. Porém, é importante lembrar que as atribuições de valor não estão desconectadas de representações quantitativas.

A coleta de dados para essa pesquisa foi feita mediante a observação direta, entrevistas semiestruturadas e grupos focais. De igual modo, é importante lembrar que apreciações subjetivas, que foram objeto dessas estratégias metodológicas, não estão alheias à realidade material objetiva e que a relação entre 0 individual e o social guarda unidade dialética. Isso significa considerar a não existência de acontecimentos ou ocorrências que se dêem a conhecer apenas como manifestação singular ou particular, da mesma forma que não há os que se revelem apenas como universalidade.

Tais incursões ao campo foram precedidas da análise documental dos principais instrumentos normativos das EPs, inclusive de seus regulamentos; de reunião no Ministério da Educação - MINED para a apresentação desse Programa e discussão sobre o trabalho a ser desenvolvido; e da realização de um pré-teste em duas EPs próximas à capital, Maputo, para aferição e validação final dos instrumentos de consulta.

Os guias de questões para os grupos focais foram elaborados com a previsão de tempo de uma hora e meia de debate e orientados por objetivos bem precisos considerando os possíveis interesses e contribuições de cada grupo de participantes, a terminologia mais apropriada a cada um deles e os critérios para a seleção de questões, tais como ser relevantes, convidativas, desprovidas de julgamentos de valor, não indutoras de respostas etc.

A aplicação da metodologia de avaliação nas escolas participantes foi iniciada com entrevistas às Direções Provinciais. Em seguida, já no ambiente das escolas, foram feitos o conhecimento dos espaços, das instalações e dos equipamentos e as entrevistas como o Diretor e Diretores Adjuntos Pedagógicos. Por último, foram realizados os grupos focais.

As pessoas que participaram dos grupos focais foram definidas por terem visto, assistido e/ou observado fatos, particularidades e circunstâncias relacionadas a aspectos e dimensões da avaliação do modelo das escolas profissionais e que se mostraram dispostas a manifestar a respeito, a darem seu testemunho apreciativo com base em suas experiências subjetivas. 
Elas representaram pequenas amostras da população compostas de forma intencional, mas coerente com os objetivos da pesquisa. Os grupos eram heterogêneos entre si com respeito aos papeis institucionais desempenhados, mas relativamente homogêneos internamente de sorte a favorecer reflexões e, ao mesmo tempo, encorajar a manifestação de opiniões divergentes.

A função de moderação foi exercida de maneira atenta com respeito a como intervir verbal e não verbalmente sem comprometimento da necessidade de assegurar a abertura, o acolhimento e a disposição para escutar posições diversas e até contrárias. Foram feitos os registros das falas, dos gestos e das interações estabelecidas pelos participantes.

Alguns preceitos em relação ao emprego da técnica dos grupos focais foram seguidos, tais como: a) proporcionar um ambiente acessível, reservado previamente para a atividade proposta, silencioso, livre de interferências de outras pessoas, com boa luminosidade, acolhedor; b) disposição dos participantes em círculo tendo em vista criar condições propícias à participação de todos os componentes; c) destinação do intervalo de tempo de uma hora e meia para a atividade pondo a salvo certa flexibilidade caso houvesse necessidade do aprofundamento do debate sobre alguma questão de interesse; d) estabelecimento de relações que favorecessem a comunicação e o diálogo entre os participantes e destes com o(a) mediador(a), considerando que grupos focais representam situações artificiais de interação discursiva entre pessoas convidadas a emitirem opiniões; e) colocação em debate apenas de questões que não fossem sensíveis a ponto de causar embaraços ou impedir a participação individual; f) abertura para contemplar questões e preocupações não previstas pelos pesquisadores e que fossem consideradas importantes para os participantes; e g) atenção à emergência de questões e conceitos de interesse para futuras investigações.

Em cada escola, foram realizados quatro grupos focais. Um formado por oito alunos observando-se a representação por curso, gênero e ano escolar. Um constituído por oito professores com representação equitativa das disciplinas socioculturais e técnico-profissionais. Um grupo específico para pais ou responsáveis substitutos, autoridades e líderes locais. E, por último, um grupo com a participação de empregadores e representantes de organizações não 
governamentais. Em relação a esses dois últimos grupos, o número de participantes dependeu da capacidade de mobilização das escolas.

Ao todo, a pesquisa contou com a participação de 380 consultados. Foram realizadas 7 reuniões com Direções Provinciais; 13 reuniões com diretores de EPs; 14 reuniões com diretores adjuntos pedagógicos; 14 grupos focais com professores (111 participantes); 14 grupos focais com alunos (125 participantes); 14 grupos focais com pais ou encarregados da educação dos alunos, autoridades e líderes locais (92 participantes) e 12 grupos focais com empregadores e representantes de organizações não governamentais (25 participantes).

Os grupos focais se reuniram em espaço fornecido pela própria EP. Não foram utilizados equipamentos de gravação ou de fotografia com a preocupação de não causar constrangimentos aos participantes. Os registros das falas foram feitos manualmente. À noite, eram complementados com informações e observações memorizadas.

As direções das escolas eram responsáveis pelo contato com os segmentos externos à escola e pelo convite à participação nos grupos focais. Alguns pais ou encarregados substitutos não mediram esforços para chegar à escola e tiveram que enfrentar alguns quilômetros de caminhada a pé.

O início das sessões dos grupos focais era marcado por explicações sobre o trabalho de avaliação das escolas profissionais, os selecionados para participar desse trabalho, a importância da participação de cada um, a maneira como os resultados a serem alcançados seriam utilizados, a possibilidade e a necessidade da expressão livre de cada um.

As diferenças de linguagem foi um dos problemas maiores encontrados na realização dos grupos focais. Entre a língua portuguesa falada em Portugal, no Brasil e em Moçambique há diferenças, por vezes significativas. Neste último, as influências das línguas africanas ali faladas sobre a língua portuguesa são importantes. Além disso, há a enorme diversidade linguística moçambicana, indicador da heterogeneidade étnica e cultural da população. O Relatório do III Seminário sobre Padronização da Ortografia das Línguas Moçambicanas, organizado por Armindo Ngunga e Osvaldo G. Faquir e publicado em 2012, relata a 
existência de 17 línguas principais ${ }^{2}$, sem contar as secundárias, e o pouco uso do português no interior do país, onde a grande maioria dos grupos focais foi realizada. Por conta disso, foi necessário recorrer à colaboração de tradutores. Houve situação em que foi preciso contar, simultaneamente, com a ajuda de mais de um intérprete. Para tanto, era preciso assegurar a boa compreensão por parte dos tradutores dos objetivos da avaliação e das questões postas à discussão.

Afora essa dificuldade de comunicação, as discussões ocorreram de forma livre, espontânea e fluida, com muitas riquezas de detalhe. O convite para participar dos grupos focais foi muito bem aceito por todos e foi possível obter um importante volume de informações. Isso se deveu, em grande parte, ao interesse e ativo envolvimento das escolas na identificação e mobilização de participantes, com particular destaque para aqueles da comunidade externa à escola. Cabe também mencionar o engajamento e a disponibilização de meios por todas as Direções Provinciais envolvidas no processo e o entusiasmo e acompanhamento dos diversos interlocutores regionais.

Após a realização da pesquisa de campo, os dois consultores elaboraram um relatório intermediário e apresentaram os resultados parciais em uma reunião, em Maputo, da qual participaram técnicos da Direção Nacional do Ensino Técnico do Ministério da Educação de Moçambique, a membros das Equipes Locais de Implementação e Desenvolvimento das Escolas Profissionais - ELIDEPs, aos representantes da Embaixada de Portugal, além de outros.

Após o retorno aos seus países de origem, Portugal e Brasil, os dois consultores elaboraram o plano de análise dos dados e realizaram a consolidação das informações colhidas. Para tanto, estabeleceram oito categorias de análise: criação das Escolas Profissionais; capacitação prévia de diretores; inovação curricular e pedagógica; prova de aptidão profissional - PAP; estágio profissional; sucesso escolar dos alunos; inserção sociocomunitária ${ }^{3}$ e aspectos marcantes do modelo EP. Essas categorias foram desdobradas em subcategorias, estreitamente ligadas às questões consideradas nos instrumentos de avaliação.

\footnotetext{
${ }^{2}$ Kimwani, Shimakonde, Ciyaawo, Emakhuwa, Echuwabu, Cinyanja, Cinyungwe, Cisena, Cibalke, Cimanyika, Cindau, Ciwute, Gitonga, Citshwa, Cicopi, Xichangana, Xirhonga.

${ }^{3}$ Categoria sobre a qual trata este artigo.
} 
O Relatório final ${ }^{4}$, concluído em dezembro de 2011, traz um sumário executivo, introdução, sistematização dos dados obtidos, síntese e recomendações, a análise dos dados colhidos e os anexos, onde podem ser encontrados os guias de questões por grupo focal e os documentos que serviram de referências para o desenvolvimento da metodologia e da interpretação dos resultados.

A análise dos elementos obtidos deu importância à recuperação das anotações nos diários reflexivos de campo produzidos a partir da observação direta e transversal, das entrevistas semiestruturadas e aos que vieram à tona nas discussões dos grupos focais. Todas essas informações foram cotejadas com os contextos em que foram obtidas, com a compreensibilidade apresentada pelos participantes a respeito das questões que Ihes foram formuladas e com os registros de gestos, reações, diferenças e/ou alterações de opiniões.

Para a interpretação dos dados, buscou-se apoio em leituras de reconhecimento do campo e sobre o tema do estudo, em reflexões críticas, inclusivas e sintéticas com respeito a significados e à totalidade social.

\section{Inserção sociocomunitária das escolas profissionais de Moçambique}

Este artigo aborda apenas os resultados de uma das dimensões tratadas pela pesquisa realizada: a referente à inserção sociocomunitária das Escolas Profissionais de Moçambique. São respostas datadas porquanto obtidas em 2011 e de uma parte dessas escolas, uma amostra de 14.

A dimensão da inserção sociocomunitária foi desdobrada nos seguintes indicadores: importância e alcance da função social desempenhada pelas Escolas Profissionais; correspondência dos conhecimentos técnicos com respeito à história, ambiência e identidade cultural locais; estratégias para adequação do ensinoaprendizagem às necessidades sociais locais; abertura da gestão à participação e sustentação das escolas por instâncias locais; cooperação técnica de profissionais e instituições da comunidade nos trabalhos das escolas; ofertas de qualificação profissional e de certificação a trabalhadores tendo em vista o desenvolvimento sociotécnico das comunidades locais; reconhecimento social e valorização dos saberes adquiridos pelos alunos.

${ }^{4}$ Disponível em: http://www.epmocambique.com/Relatorio Aval Int.pdf 


\subsection{Importância e alcance da função social desempenhada pelas Escolas Profissionais:}

Não houve quem dos entrevistados ou participantes de grupos focais, que sobre as Escolas Profissionais e o ensino profissional, não dissesse algo sobre algum aspecto relativo ao seu valor e relevância social, ao seu grande interesse para a sociedade e à sua influência sobre as comunidades. Houve, contudo, variações com respeito ao ponto ou dimensão destacada e aos argumentos utilizados para apresentar as justificativas.

Numa perspectiva mais informal e cotidiana, apareceram menções a casos de sucesso profissional de alguém que tinha passado por esse tipo de ensino ou de escola. Nesse sentido, vieram os exemplos tirados da própria família (um irmão, um primo etc.), de vizinhos ou mesmo de donos de oficinas e de empresas presentes na comunidade.

Mencionaram os bons resultados alcançados por essas pessoas, fatos ou episódios ou ações e atitudes a elas atribuídos, presenciados e/ou que se tornaram marcantes devidos às repercussões que tiveram. Ou seja, figuras ou personagens que se destacaram ou vinham se distinguindo pelo seu trabalho, pelas suas atuações no território como agentes dinâmicos de mudanças, com potencial produtivo e transformador, que demonstraram saber fazer.

Essas referências vieram acompanhadas de outras sobre carências locais de serviços profissionais, de necessidades de força de trabalho qualificada, mas que não seja muito cara, capaz de servir à população em especialidades para as quais há insuficiência de quadros técnicos.

São argumentos que levavam, por vezes, à lamentação com respeito ao atraso no desenvolvimento do país ou do território e à realidade do grande desemprego e falta de perspectivas para os jovens. Assim, da utilidade social da profissão se passava aos debates de natureza política sobre a necessidade de se combater a pobreza e se alcançar níveis de vida mais elevados. Três setores eram invariavelmente citados como prioritários: a agricultura de subsistência alimentar; a eletricidade para atender necessidades da população e como base para o desenvolvimento de outras atividades produtivas e a hotelaria pelo seu préstimo crucial à expansão do turismo. 
Foram, também, citados alguns aportes da educação profissional ao desenvolvimento tecnológico do país e à recuperação de tradições comunitárias locais relacionadas aos saberes tradicionais. Por exemplo, o caso da premiação de um aluno que desenvolveu um sabão em pó com aroma de bálsamo a partir da raiz de uma árvore nativa; a redescoberta da batata-reno considerada variedade extinta graças aos ensaios realizados por professores e alunos; a reintrodução e o aumento da produtividade no cultivo de um tipo de manga, que havia desaparecido da província.

Contudo, houve quem justificasse a importância e a função social das Escolas Profissionais e do ensino técnico considerando-os como alternativa de combate à marginalidade e à delinquência. Nesse sentido, a correlação se estabeleceu entre a formação para o trabalho e a promoção da moralidade e da disciplina pessoal.

Em menor número, mas também presentes, surgiram os argumentos de que essas escolas são as mais convenientes para beneficiar pessoas carentes, aqueles que têm dificuldade para aprender e os jovens mais velhos com histórico de insucesso escolar, mas que precisam se tornar independentes dos pais e garantir seu próprio sustento.

Discursos mais lapidados lembraram a importância das Escolas Profissionais como modelo pedagógico comprometido com a emancipação social, como locais de produção de saberes e de cultura, como motores de organização coletiva, como ambientes de reciprocidade e de relações democráticas, como agências de solidariedade e de apoio ao associativismo.

\subsection{Correspondência dos conhecimentos técnicos com respeito à história, ambiência e identidade cultural locais:}

Os diretores e professores ouvidos alegaram que não tem sido fácil para as Escolas Profissionais desenvolverem essa sintonia, apesar do propósito do modelo pedagógico adotado de buscar o atendimento das necessidades e demandas comunitárias, de fazer com que os cursos correspondam e dialoguem com as especificidades históricas e identidades econômicas, sociais e culturais dos territórios.

À dimensão técnica da formação, os interlocutores da pesquisa associavam a importância da educação em valores e crenças importantes para o desenvolvimento 
do sentimento de pertencimento comunitário e da atenção às normas de convivência, aos costumes, hábitos e tradições.

Houve, também, destaque para a necessidade de preparar os jovens à participação em estratégias individuais e coletivas de trabalho criadas pelos setores populares e o reforço, nos currículos, dos conteúdos e das atividades de educação cooperativa e autogestionária.

Porém, as discussões realizadas evidenciaram ser esse um ponto ainda frágil das Escolas Profissionais, muito embora ainda em 1972, portanto quatro décadas antes da pesquisa realizada, Amadou Hampaté $\mathrm{Ba}$, maliense dedicado à administração pública, à diplomacia e à UNESCO e com importantes estudos sobre a tradição oral de povos tradicionais, já o tivesse reclamado em suas análises sobre aspectos da civilização africana:

\begin{abstract}
Actualmente, reconhecendo a importância do património cultural representado pela sabedoria popular e pelas práticas de educação tradicional, os governos africanos tentam adoptar políticas culturais para resgatar o capital de conhecimentos e de cultura acumulados nas aldeias para que não ocorra a perda do património cultural tradicional, pois é sabido que, "nas sociedades tradicionais, quando morre um ancião, perde-se uma biblioteca". (BA, 1972). (aspas no original).
\end{abstract}

\title{
5.3. Estratégias para adequação do ensino-aprendizagem às necessidades sociais locais:
}

Esse é um ponto sobre o qual os diretores e professores ouvidos reconheceram como exemplo das dificuldades encontradas para a superação de resquícios do modelo pedagógico tradicional das antigas escolas de artes e ofícios. Isso implicava várias coisas que não estavam sendo atendidas, tais como adequações em currículos, desenvolvimento de materiais pedagógicos específicos, capacitação de docentes, disponibilidade de meios de transporte, condições para capilarizar a divulgação das escolas, aproximação das lideranças locais, dinamização dos conselhos de escola, celebração de convênios e parcerias, avaliação contínua dos resultados alcançados e acompanhamento dos egressos.

As justificativas apresentadas por eles diziam respeito à escassez de recursos. No caso do acompanhamento da inserção socioprofissional dos alunos graduados consideravam muito precárias as informações que dispunham, o que pode ser 
considerado como um aspecto importante com respeito uma variável desfavorável à inserção social e comunitária das escolas.

Salientaram, porém, as vantagens que dispunham de ter prerrogativas de autonomia cultural, fator considerado por eles como muito importante para o cultivo da sensibilidade institucional com respeito às características das comunidades atendidas.

Apesar das limitações existentes, foram dados diversos depoimentos sobre ações das escolas de valorização da diversidade e da riqueza culturais locais, os esforços empreendidos para realizar a articulação com as comunidades inclusive com a promoção de atividades culturais de teatro e música e abertura da escola à participação das comunidades.

De fato a implicação comprometida, refletida e partilhada a respeito das estratégias para adequação do ensino-aprendizagem às necessidades sociais locais requer o envolvimento não apenas das escolas profissionais, mas de todos os setores das comunidades. Esses laços demandam ser trabalhados para que os processos de cooperação na busca dessa adequação possam se desenvolver. Tais dificuldades evidenciam, por outro lado, as dificuldades para fortalecer os vínculos entre as escolas e as comunidades, para fazer face à fragmentação e segregação de que a educação profissional tende a experimentar mesmo em contextos de organização social comunitária.

\subsection{Abertura da gestão à participação e sustentação das escolas por instâncias locais:}

As Escolas Profissionais de Moçambique, segundo os diretores e professores ouvidos, não têm tido, em geral, as condições necessárias para exercer plenamente a autonomia, que lhes é concedida no plano administrativo e pedagógico. Delas estava sendo solicitado, inclusive, empenho para a conquista de sua autonomia financeira.

A falta de aparelhamento e as dificuldades enfrentadas pelos potenciais parceiros para viabilizar o apoio requerido às escolas e à sua gestão foram citadas como motivos das dificuldades que elas estavam encontrando para exercer suas finalidades sóciocomunitárias de promoção do desenvolvimento local.

Excetuando a Hidroelétrica de Cahora Bassa, empresa moçambicana situada no município de Songo e na província de Tete, distinguida com prêmios 
internacionais de responsabilidade social ${ }^{5}$ e com atuação no Plano Integrado de Desenvolvimento do Vale do Zambeze, outras empresas de maior porte não estavam oferecendo qualquer patrocínio às Escolas Profissionais.

Por outro lado, as pequenas empresas locais alegavam ter dificuldades para subsidiar material e financeiramente a criação e o desenvolvimento dessas escolas. $\mathrm{Na}$ interlocução realizada para fins desta pesquisa, ouviu-se deles demandas para que os alunos estagiários levassem ferramentas, pois em suas oficinas havia número insuficiente delas. Requeriam, também, das escolas o provimento de insumos necessários à prática dos estagiários. Houve aqueles que esperavam receber compensações do governo, tais como incentivos para obtenção de maquinários e de materiais, como forma de reparação das despesas que tinham no apoio à realização dos estágios dos alunos.

Os diretores e professores expuseram as dificuldades que estavam tendo para implicar também as famílias dos alunos na gestão e no arrimo às escolas. Esse era mais um dos fatores das atribulações que passavam para conseguir avançar no enraizamento sociocomunitário e manter os Conselhos das escolas em funcionamento regular. Grande parte das famílias, além das diversas carências próprias do estado de pobreza, precisava enfrentar condições de transporte muito limitadas e deslocamentos a pé para ali chegarem.

Os diretores e professores afirmaram que as dotações governamentais não estavam sendo suficientes para cobrir as despesas correntes e os investimentos necessários à melhoria das condições de operação das escolas e que precisavam aprofundar seus conhecimentos sobre como ampliar e tornar mais eficazes suas bases de apoio sociocomunitário.

Isso implicava em expandir suas ações no contexto local para melhor conhecê-lo e descobrir potenciais recursos e meios, o que em si também requeria contar com infraestrutura física, administrativa, financeira e de pessoal.

Dentre as estratégicas mencionadas pelos intervenientes internos e externos às escolas com respeito à conquista de apoios e solidariedades em favor delas -

\footnotetext{
${ }^{5}$ Guiados, usualmente, por paradigma distante e até mesmo oposto ao conceito de responsabilidade social entendida como cuidados éticos na maneira de atuar junto às comunidades, na escolha do critério da emancipação social para definir com quem se comprometer e cooperar, nas relações de parceria estabelecidas, na compreensão das diferentes formas de compreender a relação entre conhecimento e autoridade, na definição dos objetivos e rumos das ações desenvolvidas, enfim, com o compromisso com a transformação social.
} 
uma perspectiva cara aos pesquisados entendida como amparo, respaldo, reciprocidade e coparticipação - apareceram sugestões como: campanhas sobre a importância e necessidade da educação profissional e que ela deve ser assumida como responsabilidade de todos; estímulo à ajuda das empresas; envio de cartas; captação de recursos mediante a oferta de serviços à comunidade; criação e manutenção de páginas na Internet de divulgação das escolas; criação de associações de amigos das escolas; divulgação das produções dos alunos; promoção da semana do ensino técnico com visitas à escola e realização de oficinas para alunos da sétima classe das escolas primárias; organização de palestras, encontros e atividades de confraternização; criação de projetos de interesse comum; identificação e mobilização de saberes, recursos e disponibilidades de ajuda existentes na comunidade; mecanismos para que as comunidades possam acompanhar os processos e os resultados da gestão das EP; dentre outras.

Foram lembradas a esse respeito as recomendações e orientações que constam do Diploma Ministerial n. 75/2010 de criação das Elidep - Equipes Locais de Implementação e Desenvolvimento das Escolas Profissionais e do Regulamento Geral das Escolas e Institutos Técnicos do País.

\subsection{Cooperação técnica de profissionais e instituições da comunidade nos trabalhos das escolas:}

O Regulamento das Escolas Profissionais incluiu a alternativa do aproveitamento das experiências e saberes existentes na comunidade para o desenvolvimento do trabalho pedagógico. Trata-se de oportunidade de contato dos estudantes com o ambiente e a vida social e cultural do seu meio comunitário por meio da interação com empregadores, líderes e profissionais locais, inclusive com ex-alunos da própria escola.

Porém, não estava sendo uma tarefa simples para essas escolas criar e assegurar tais adesões, parcerias e cooperação. Elas não dispunham de recursos financeiros para remunerar tais colaborações e nem estavam autorizadas a formalizá-las.

Por outro lado, se interpunham questões de ordem pedagógica e organizacional, que requeriam o acompanhamento desses cooperantes por professores das escolas. Essas diziam respeito ao saber se ocupar de adolescentes e jovens, intimidade com vocabulários técnicos, observação de normas de 
segurança do trabalho, possibilidade de se comunicar na língua portuguesa. Foi aventada, inclusive, a necessidade e a possibilidade de promoção da própria escola de processos de legitimação e certificação dos saberes e experiências dessas pessoas da comunidade para seu envolvimento nas atividades pedagógicas.

A cota de colaboração ao trabalho pedagógico oferecida pelos empregadores mereceu uma atenção destacada, a começar pela participação em Conselhos de Escola. Houve também menção à importância de outros apoios que eles estavam dando ou poderiam dar, tais como: a oferta de oportunidades de estágios, a participação em júris para avaliar alunos submetidos a provas de aptidão profissional, a realização de palestras sobre assuntos técnicos e de informação profissional, a liberação de funcionários das empresas para eventuais colaborações nas escolas, consertos de máquinas avariadas das escolas, suprimentos de orientações técnicas, discussão sobre necessidades e demandas de formação profissional, atualização técnica de professores, estímulo e orientação de alunos à criação de suas empresas, contratação preferencial ou indicação de egressos das EP para recrutamento por outros empregadores.

Os empregadores alegaram, contudo, que Ihes faltavam mais conhecimentos sobre as escolas, suas oficinas e o que tem sido feito por elas para que pudessem melhor se engajar nos seus trabalhos.

Sobre a disponibilização de locais para estágios, colocaram alguns comedimentos. Alegaram falta de espaço físico nas suas oficinas, a quantidade e diversidade limitada das ferramentas disponíveis, os custos que teriam que arcar com materiais e outros insumos utilizados pelos estagiários. Comentaram, além disso, o investimento que tinham que fazer para fazer face à precária formação prática com a qual os alunos chegam para estagiar. Isso estaria a lhes exigir o trabalho de ensiná-los desde o mais elementar começo.

\subsection{Qualificação e certificação de trabalhadores adultos:}

Tais linhas de atuação apareceram em interlocuções durante a pesquisa de campo como forma de favorecer o desenvolvimento sociotécnico das comunidades locais. Os encarregados de educação dos alunos das Escolas Profissionais, pessoas que os acompanham, orientam e participam das suas vidas escolares e que fazem a articulação das escolas com as famílias se mostraram muito interessados 
na implementação dessas propostas. Da mesma forma se manifestaram alguns pais. O tema também esteve presente em entrevistas com direções provinciais e diretores das escolas.

Trata-se da formação inicial e continuada de adultos, de ofertas de grande relevância social previstas no Regulamento das Escolas Profissionais e que já têm sido realidade em algumas delas por meio do desenvolvimento de cursos de inglês e de informática. Além desses, houve indicação da necessidade da oferta de cursos no domínio da agricultura e sobre empreendedorismo, corte e costura, culinária, avicultura, construção civil e serviços de mesa e bar.

Levantou-se, inclusive, a hipótese de que essa via de desenvolvimento de atividades formativas de trabalhadores poderia ser de interesse das empresas, que ao pagarem pela oferta desses serviços contribuiriam com o aumento das receitas das escolas. Aventaram a possibilidade de que tais cursos pudessem ser oferecidos utilizando-se a infraestrutura de oficinas das empresas.

Porém, verificou-se não haver naquele momento apoio material e financeiro governamental para o desenvolvimento dessas atividades, nem as escolas conseguiriam lançar mão dos seus professores para tal já que eles não deveriam ser desviados das funções docentes para as quais foram originalmente designados.

Apurou-se, porém, que comunidades próximas estavam se beneficiando das experiências e conhecimentos desenvolvidos pelas escolas dedicadas ao ensinoaprendizagem da agricultura, especialmente com relação às inovações referentes às modificações de processos produtivos, intervenções fitossanitárias e cultivo de novos produtos e que isso estaria provocando a melhoria da produtividade dos seus plantios e hortas.

As interações das escolas com as comunidades locais estavam, segundo se concluiu das interlocuções nos grupos focais e entrevistas, contagiando famílias e pessoas a mudarem costumes, hábitos e tradições em favor de uma melhor qualidade de vida.

Portanto, o papel educacional e indutor do desenvolvimento local das Escolas Profissionais, de certa forma, por conta da promoção de projetos transversais, dos contatos dos alunos e professores com a vida social e cultural do meio comunitário e dos vínculos aí estabelecidos, acaba sendo ampliado com respeito ao combate da pobreza no país, ao incentivo às pequenas inovações produtivas e à disseminação 
de novas técnicas e novos conhecimentos. Isso se volta a favor da própria escola no sentido de despertar o interesse da população do entorno a conhecê-la de perto e com ela estabelecer parcerias.

\subsection{Reconhecimento social e valorização dos saberes adquiridos pelos alunos:}

A Prova de Aptidão Profissional é um procedimento que as Escolas Profissionais utilizam para apreciar o desempenho, validar a formação dos alunos e legitimar a conclusão do curso realizado. Ela compreende a apresentação e defesa, perante um júri, de um projeto e sua concretização na forma de um produto ou de uma atuação técnica específica, acompanhados de um relatório final.

Por meio dessa prova, espera-se que o concluinte demonstre ter adquirido as habilidades e conhecimentos profissionais requeridos ao exercício da ocupação ou profissão para a qual se preparou. Ele é avaliado por uma comissão, que pode contar com a participação de representantes do nicho socioprofissional ao qual se destina, da comunidade, de setores das direções provinciais e professores.

Os produtos submetidos pelos alunos nessas provas são, em geral, bens tangíveis destinados ao uso de suas famílias, comunidades ou mesmo da própria escola. Já quando se trata de atuações específicas apresentadas para avaliação, essas se referem a demonstrações que evidenciem o domínio de determinadas técnicas.

Essas provas podem ter caráter individual ou se referir a um projeto coletivo. Neste último caso, envolvem desafios mais complexos e permitem avaliar também a capacidade de trabalhar em grupo. São momentos memoráveis para cada um que de uma forma ou outra participa do processo.

Seja numa ou outra situação, elas possuem uma forte dimensão sociocomunitária e são assistidas, de forma comovida, por membros da família, encarregados de educação, pessoas do entorno da escola e por representantes de empresas interessados no recrutamento de trabalhadores com habilidades e saberes comprovados.

É um momento importante de reconhecimento social e valorização dos saberes adquiridos pelos alunos, fundamental para os processos de desenvolvimento de suas profissionalidades. Para as escolas, elas permitem dar 
visibilidade ao seu trabalho pedagógico, mostrar resultados de aprendizagens, trazer familiares, encarregados de educação e pessoas da comunidade para conhecê-las.

Os alunos expressaram durante a pesquisa de campo que a realização dessas provas traz motivos de muito orgulho para si pela oportunidade de superação pessoal e pela chance de poder evidenciar domínios de técnicas de intervenção profissional ou de produzir um bem concreto de utilidade seja para suas famílias, vizinhos, comunidades ou para a própria escola.

Os empregadores ouvidos fizeram, porém, algumas ponderações no sentido de considerar muito elementar a formação recebida pelos alunos, o que não thes daria grandes possibilidades de emprego e nem Ihes proporcionaria capacidade de adaptação às variações do mercado de trabalho.

Em vista disso, recomendaram investimento na formação para o chamado autoemprego, para o desenvolvimento da capacidade de fazer planos de negócio. Reforçaram essa indicação com a observação de que muitos dos alunos que eles têm recebido para a realização de estágio em suas empresas se mostram desinteressados em aprender o que eles se propõem a lhes ensinar.

Nesse sentido, veem que seria importante investir na orientação profissional dos alunos, pois eles têm se matriculado nessas Escolas Profissionais ainda muito jovens e imaturos com respeito ao que gostariam de se dedicar profissionalmente.

Não apenas os empregadores assim se posicionaram com respeito à inserção profissional dos alunos após a conclusão dos estudos na Escola Profissional. Todos os que foram ouvidos, representantes de direções provinciais, diretores das escolas, professores, encarregados de educação, autoridades locais e, inclusive, os próprios alunos se mostraram preocupados com as dificuldades para encontrar um posto de trabalho depois da conclusão do curso.

De forma consensual, eles também privilegiaram a alternativa do investimento em pequenos empreendimentos, por acreditarem que a inserção socioprofissional mediante $\mathrm{o}$ assalariamento tem ficado cada vez mais difícil em face das características que o mercado de trabalho vem assumindo por conta das mudanças tecnológicas e do aumento do nível de competição entre os próprios trabalhadores.

Assim, apontaram para a necessidade da inversão por parte das Escolas Profissionais em conteúdos curriculares relacionados à gestão, em desenvolvimento 
de habilidades que estimulem a criatividade e impulsionem a capacidade de inovar processos, produtos e serviços.

Da parte do governo, destacaram a necessidade de adoção de políticas que ajudem os ex-alunos das Escolas Profissionais a superarem as dificuldades que possuem do ponto de vista financeiro para constituírem seus pequenos empreendimentos.

Essas abrangeriam diversas formas de apoio e incentivos tais como acesso gratuito a kits de ferramentas, a linhas de créditos preferenciais, a incubadoras de empresas, a orientações sobre cooperativismo e associativismo. Além disso, caberia ao governo abrir oportunidades de absorção dos serviços desses pequenos empreendimentos. Por exemplo, mediante a criação de programas de construção e reparação de habitações populares e de equipamentos sociais e comunitários.

\section{Considerações finais}

Não é simples discorrer sobre a inserção sóciocomunitária como alicerce de processos formativos de escolas profissionais. Colocá-la em prática é ainda mais complicado, intricado, enigmático, penoso e oneroso. Por isso, mesmo o pouco que se conquista nesse desafio se apresenta com um halo de excepcionalidade e astúcia.

Groppo (2013, p.10) entende que relações sociais que correspondam ao atendimento de "[...] necessidades propriamente humanas: sobrevivência, cuidado e identidade (em seu viés comunitário) e liberdade, autonomia e criação (em seu viés societário)" são os ingredientes da lógica ou princípio sociocomunitário.

Ele considera, entretanto, que essa lógica tem sido instrumentalizada em favor da integração sistêmica ao mundo do capital, mas que pode ter seus indícios identificados em realidades educacionais concretas tais como as que promovem as construções de valores coletivos, de identidades, do sentimento de pertença, de redes e relações de proteção e segurança, de relações de solidariedade socioeconômica e de redes de criação artístico-cultural. (GROPPO, 2013).

A pesquisa realizada permitiu ver alguns desses indícios nas práticas pedagógicas das Escolas Profissionais de Moçambique. Mas, também, possibilitou divisar e presenciar o quanto é ampla e complexa a realidade em que estão imersas, 
com a qual interagem e da qual recebem influências e pressões positivas e negativas.

Elas experimentam um misto de oportunidades e de ameaças, conflitos nem sempre explícitos, a necessidade da desmontagem de preconceitos, o combate à indiferença, o difícil equilíbrio na construção do interconhecimento. Acordos sobre seu futuro não podem ser feitos, mas alguns dos seus resultados incentivam a realizar apostas.

Isso porque, de um lado, o próprio desenvolvimento humano reclama a não existência de limites que cerceiem seus caminhos. Mas, por outro, as incertezas e as complexidades envolvidas são irrefutáveis enquanto possibilidades.

Quando se propôs que a inserção sociocomunitária se constituísse como alicerce de processos formativos das Escolas Profissionais de Moçambique um grande desafio estava sendo lançado, pois isso significava também realizar a articulação da educação com as políticas de desenvolvimento local, tomar a educação não como uma área dentre outras importantes para as comunidades envolvidas, mas dela fazer um eixo estruturante do desenvolvimento local, do fomento das relações de proximidade e de convivência solidária.

A pesquisa constatou a importância atribuída pelos interlocutores que dela participaram às relações de caráter local, consideradas até mais significativas do que as de caráter nacional, talvez porque essas últimas estavam de certo modo distantes dos seus quotidianos. Nesse sentido, percebeu-se que a inserção sociocomunitária das escolas profissionais representa oportunidades para realizar ações significativas para as pessoas envolvidas.

Nesses termos, o desenvolvimento educacional ou dessas escolas profissionais aparece como indissociável do desenvolvimento comunitário, embora o valor das aprendizagens por elas proporcionadas ainda estivesse em busca de um lugar garantido no coração da própria vida comunitária.

A pesquisa realizada evidenciou, assim, a amplitude político-antropológica da inserção sociocomunitária das escolas profissionais de Moçambique, revelando muitos dos desafios para a materialização desse desiderato de ir mais longe e mais fundo na transformação dessas escolas em lugares históricos, identitários e relacionais das suas comunidades. 
Inserção sociocomunitária se refere às dinâmicas de entretecimento de laços sociais e culturais mediante convivências, inter-relacionamentos, intercomunicações, compartilhamentos de valores, realizações conjuntas, implicações recíprocas e formação de sentimentos de mútuo pertencimento.

Se as Escolas Profissionais de Moçambique se mostraram aquém das atribuições que Ihes foram designadas nessa matéria, elas se revelaram conscientes da necessidade de se afirmarem como sujeitos capazes de ocuparem e construírem esse lugar de intercalação de práticas sociais.

Desafios de todo tipo foram explicitados, desde como captar e ouvir as comunidades do entorno até como construir redes de convivência mais solidárias, justas e dignas e como conseguir captar a concretude histórico-social das relações humanas comunitárias, vividas na sua singularidade.

É preciso ter em conta a situação social do país, marcada por desigualdades sociais e pela extrema pobreza. Assim, a inserção sociocomunitária dessas escolas profissionais não pode se furtar à necessidade de fazer convergir os valores e princípios da educação democrática e as práticas e valores da educação das comunidades tradicionais, buscando sempre, nesse movimento, as congruências com a defesa da dignidade humana.

O princípio básico de buscar na vida comunitária o alicerce para essas escolas significa reconhecer que é preciso dar conta e crédito ao modo de vida simples das comunidades, saber que tecnologias e livros do mundo letrado nem sempre estão disponíveis, que ferramentas e equipamentos tradicionais ainda podem ter seu papel, que a dispersão e o isolamento das comunidades podem limitar as condições básicas de vida; que índices de pobreza e de analfabetismo precisam ser minimizados; que tradições culturais encontram-se enraizadas; que a tendência ao conservadorismo está presente; que as condições de existência ainda são pouco dignas para muitos; que o regime do patriarcado e da gerontocracia são elementos modeladores das culturas locais, que as representações sobre a mulher tendem a reservá-las para funções de pouco destaque na sociedade, que dia a dia cresce o número dos casamentos precoces dos adolescentes, que há preconceitos mútuos entre a escola regular e os agentes educacionais tradicionais.

Todos esses desafios com os quais a pesquisa se deparou são coerentes com a realidade de uma sociedade multiétnica como a moçambicana. Cabe às 
escolas profissionais, no seu esforço de realizar sua inserção sociocomunitária, promover diálogos, viabilizar intercâmbios, discutir valores, realizar aberturas à participação social, construir sentimentos de mútuo pertencimento. No caso específico da realidade moçambicana, é preciso considerar as fissuras deixadas pelos conflitos passados, não apenas decorrentes da luta contra o colonizador, e as que ainda se estão produzindo pelas contendas atuais.

Pode-se, assim, concluir que, como política cultural de inserção sociocomunitária, encomendas importantes foram feitas às escolas profissionais de Moçambique, muitas das quais estavam carentes de realização. Nesses termos, considera-se que a prioridade a ser dada à valorização da cultura local no âmbito do currículo e dos processos educativos, a promoção de investigações com a participação das comunidades, a divulgação das tradições culturais e o incentivo às manifestações culturais comunitárias.

\section{Referências}

ANDER-EGG, Ezequiel. Metodologia y práctica del desarrollo de la comunidad. Buenos Aires: El Ateneo, 1982.

AZEVEDO, Joaquim. Projetar o ensino profissional nestes tempos instáveis e incertos. Parte I, cap. 1. In: ORVALHO, Luísa; ALVES, José Matias; (coord.). (Re) encantar e projetar o ensino profissional no século XXI. Porto: Universidade Católica Portuguesa, Faculdade de Educação e Psicologia, maio 2017, p.8-21. Disponível

em: http://www.fep.porto.ucp.pt/sites/default/files/files/FEP/SAME/e book 2405 2017.p df.

AZEVEDO, Joaquim; ABREU, José M. Ensino profissional em África: Falácia ou oportunidade? O caso das Escolas Profissionais em Moçambique. Revista Portuguesa de Investigação Educacional, Lisboa, n. 5, p. 5-42, 2007. Disponível em: http://www.joaquimazevedo.com/Images/BibTex/3395527680EP Africa JA.pdf. Acesso em 27 jul. 2018.

BA, Amadou Hampâté. Aspects de la civilisation africaine : personne, culture, religion. Paris: Présence Africaine, 1972. 140p

BRAGA, Paula. Ensino profissional em Moçambique: acreditar num futuro melhor. Revista Moçambique, p. 59-62, abril 2018. Disponível em: https://www.paulabraga.pt/wp-content/uploads/2018/04/pdf light 54 62-1.pdf 
CARDOSO, J. O conhecimento nas comunidades. In: RODRIGUES, L. C.; MARTINS, J. F.; FERNANDES, T. M. (Orgs.). Manual de Cooperação para o Desenvolvimento. Oeiras: INA Editora, 2011, p. 333-343.

CASTIANO, José P. O currículo local como espaço social de coexistência de discursos: estudo de caso nos distritos de Báruè, de Sussundenga e da Cidade de Chimoio - Moçambique. Revista E-Curriculum, São Paulo, v. 1, n. 1, dez.- jul. 2005-2006. Disponível em: http://www.redalyc.org/html/766/76610103/. Acesso em: 27 jul. 2018.

CASTRO, José Manuel; MACHADO, Lucília. Avaliação Internacional do Modelo Curricular e Pedagógico das Escolas Profissionais de Moçambique. Relatório Final, $2011.2106 p$ Disponível em: http://www.epmocambique.com/Relatorio Aval Int.pdf

Lições de África: O modelo curricular das Escolas Profissionais moçambicanas. Trabalho \& Educação, v. 23, n.1, p. 147-160. 2014. Disponível em: https://seer.ufmg.br/index.php/trabedu/article/view/7694/5936. Acesso em 27 jul. 2018.

GROPPO, Luis Antonio. Educação sociocomunitária e integração sistêmica: fundamentos para uma crítica das intervenções educacionais não formais contemporâneas. Acta Científica, v. 22, n. 1, p. 9-21, jan.- abr. 2013.

LIBOMBO, Sérgio Elias et al. Associações agrícolas e desenvolvimento local em Moçambique: perspectivas e desafios da Associação Livre de Mahubo. Revista NERA, Presidente Prudente, ano 20, n. 38, Dossiê, p. 132-150, 2017. Disponível em: http://revista.fct.unesp.br/index.php/nera/article/viewFile/5115/4059. Acesso: 25 jul. 2018.

MARTINS, Sofia Oliveira; AZEVEDO, Joaquim. Educação e desenvolvimento sociocomunitário pela voz de elementos-chave da comunidade. In: Educação, Territórios e Desenvolvimento Humano: Atas do I Seminário Internacional, V. II Comunicações Livres. Porto: Universidade Católica Portuguesa. Faculdade de Educação e Psicologia, 2015.

NAMUHOLOPA, Óscar Morais Fernando; VETTORASSI, Andréa. Identidade ou identidades? Que análise se pode fazer da pluralidade cultural de Moçambique? Argumentos, Montes Claros, v.14, n.1, p.118-137, jan/jun 2017.

NGUIRAZE, André Camanguira; AIRES, Jussara Danielle Martins. Moçambique: processos de participação das comunidades rurais no desenvolvimento local. Revista IDeAS, v. 5, n. 1, p. 30-65, 2011.

NGUNGA, Armindo; FAQUIR, Osvaldo G. Padronização da Ortografia das Línguas Moçambicanas. Relatório do III Seminário. Colecção: As nossas línguas III, Centro de Estudos Africanos (CEA) - UEM: Maputo, 2012, 358p. 
SANTOS, Boaventura de Sousa. Para além do pensamento abissal. Das linhas globais a uma ecologia de saberes. Novos Estudos Cebrap, n.79, nov. 2007, p. 7194. Disponível em: http://www.scielo.br/pdf/nec/n79/04.pdf

SAWAIA, Bader B. Comunidade: A apropriação científica de um conceito tão antigo quanto a humanidade. In: CAMPOS, Regina Helena de Freitas (org.). Psicologia social comunitária: da solidariedade à autonomia. Petrópolis: Vozes, 1996. p.35-53.

VERRANGIA, Douglas. Conhecimentos tradicionais de matriz africana e afrobrasileira no ensino de Ciências: um grande desafio. Revista África e Africanidades, ano 2, n. 8, fev. 2010. Disponível em: http://www.africaeafricanidades.com.br/documentos/conhecimentos tradicionais ma triz afro-brasileira ensino ciencias.pdf

Recebido em: 06 de agosto de 2018. Aprovado em: 09 de outubro de 2018. Publicado em: 22 de novembro de 2018. 